\title{
Política exterior autonómica y el boicot argentino al embargo de Estados Unidos a Cuba ${ }^{1}$
}

\author{
María Teresa Piñero ${ }^{2}$
}

\section{Resumen}

Este trabajo aborda el campo de las ideas y hechos políticos que en la década del 70 del siglo XX en Argentina, delinearon el momento que Juan Carlos Puig llamaría de «autonomía heterodoxa», una posición estratégica de política de relaciones exteriores. En este periodo, se producen distintas acciones que oscilaban entre el enfrentamiento abierto con Estados Unidos, en el marco de las posiciones en los organismos internacionales, la continuidad de los acuerdos comerciales con este país, el acercamiento a los países del Este y a los del Tercer mundo. En ese contexto se produce lo que se designaría como el boicot argentino al embargo cubano, el que analizado como un caso paradigmático de autonomía heterodoxa conllevó una estrategia comercial, que beneficiando a empresarios locales, nacionales y transnacionales permitió su concreción.

Palabras clave: Política exterior argentinaAutonomía-Boicot embargo a Cuba-Relaciones comerciales-Estados Unidos

\begin{abstract}
:
This project addresses the political ideas and events that, in the '70s in Argentina, gave rise to what Juan Carlos Puig called «heterodox autonomy», a strategic position in the politics of foreign relations. Different actions took place in this period, from the open confrontation with the United States, regarding positions in international organisms, to the continuation of commercial agreements with this country, and the rapprochement with countries of the East and of the third world. In this context, it developed what would be referred to as the Argentinean boycott to the Cuban embargo, which, analyzed as a paradigmatic occurrence of heterodox autonomy, entailed a commercial strategy that, benefiting local, national and transnational companies, allowed its fruition.
\end{abstract}

Keywords: Argentina's foreign policy Autonomy - Boycott to the Cuban embargo - Commercial relationships - United States

${ }^{1}$ Trabajo recibido el 25/07/2016. Aceptado el 11/11/2016.

2 Abogada, Magister en Relaciones Internacionales y Doctora en Derecho y Ciencias Sociales (Universidad Nacional de Córdoba). Profesora Titular de la Universidad Nacional de Córdoba. Directora Alterna Doctorado en Ciencia Política del Centro de Estudios Avanzados de la Universidad Nacional de Córdoba. Contacto: mariateresapinero@ outlook.com.ar 


\section{Introducción}

Cuenta la anécdota que a la vuelta de su visita a Vietnam, Fidel Castro le comenta a un periodista: «Estados Unidos vendrá a dialogar con nosotros cuando tenga un Presidente negro y haya en el mundo un Papa latinoamericano». ${ }^{3}$ Fidel habla en los años setenta ${ }^{4}$, la época de la Guerra Fría; Nixon juraba como Presidente de Estados Unidos en su segundo mandato, se aseguraba el endurecimiento del bloqueo a Cuba. Por otra parte, en Argentina se reiniciaban las relaciones con este país y se tomaban ciertas medidas que según especialistas en relaciones internacionales, implicaron un desafío a la política de Estados Unidos respecto a Cuba y a sus relaciones con América Latina en general.

\section{La disputa entre el Norte y el Sur por las inversiones}

Desde 1947 dos temas relacionados entre sí -intereses mundiales y asuntos referidos a la Guerra Fría- modelaron las políticas norteamericanas respecto a América Latina. Como resultado, la región readquiere importancia con el surgimiento de la Cuba castrista en 1959 y la amenaza comunista.

En este orden, los regímenes internacionales establecidos luego de la Segunda Guerra Mundial reflejaban los intereses económicos y las normas de Estados Unidos; un orden económico internacional abierto que el FMI, Banco Mundial y el Gatt ${ }^{5}$ debían reforzar, en el que las importantes transferencias de recursos a través de planes, como el Marshall a Europa, la Alianza para el Progreso de Estados Unidos para América Latina, estaban destinados a construir espacios de mercados ampliados y, en ese orden, las corporaciones multinacionales norteamericanas eran los ejes de la transferencia del capital y la tecnología a los otros países.

El momento político de los años citados implica un posicionamiento inédito para los países de la periferia. ${ }^{6}$ Desde la conferencia de Bandung

\footnotetext{
${ }^{3}$ http://www.clarin.com/mundo/Fidel-Castro-Cuba-EE-UU-asombrosa-prediccion973_0_1399060294.html.

${ }^{4}$ En 2014 ambas condiciones se dieron y cumpliéndose la profecía de Castro, Estados Unidos accede a tomar algunas medidas de acercamiento, que abre esperanzas sobre la posibilidad de iniciar el desbloqueo de la Isla.

${ }^{5}$ General Agreement on Tariffs and Trade

${ }^{6}$ Nos referimos a países periféricos- siguiendo la distinción entre centro y periferia tribu-
} 
de 1955 que inicia una discusión sobre los procesos de descolonización, hasta el cese del boicot de la OPEP en 1974 a los países desarrollados, transcurren periodos de gran actividad defensiva y estratégica de los países periféricos, cuyos logros se debieron a lo que un autor liberal como Krasner denomina «capacidad de formular un sistema de ideas coherentes que establezca la agenda de las negociaciones internacionales y cimente la unidad del Tercer Mundo». ${ }^{7}$

Si durante los años '50 se reconoció la existencia del derecho de los países colonizados a reclamar por su posición materialmente desigual en el orden internacional y durante los años 60 se sientan las bases para estrategias ofensivas-defensivas y negociaciones para obtener presencia en órganos y poder en foros multilaterales, es en los años 70 cuando las acciones del tercer mundo se definieron en términos de norte-sur marcadas por el cuestionamiento a las posiciones capitalistas de dominación por parte de los países centrales.

Estas posiciones, que establecieron un nuevo marco de negociación con los países centrales, partían del cuestionamiento al orden liberal internacional existente -cimentado en regímenes, principios y normas orientados por el mercado ${ }^{8}$ - y su sustitución por otro fundado en asignaciones «autoritativas» ${ }^{9}$ (sic). ${ }^{10}$ A esto se lo conoce como el reclamo por un «nuevo orden económico internacional» (NOEI), que cubría un amplio rango de áreas temáticas que incluían el comercio, productos de primera necesidad, ayuda, deudas, el espacio, empresas multinacionales, el periodismo y fletes.

En las explicaciones de Wallerstein, ${ }^{11}$ en la década del sesenta ya estaba abierta la confrontación de los países del tercer mundo al consenso

taria de la CEPAL y la teoría de la dependencia- en un sentido de sinónimo de países del tercer mundo o en desarrollo (tal como se los nominaba en los años 70) para designar el grupo de países que por contraposición a los «centrales» no tienen el poder de construir el orden económico internacional.

${ }^{7}$ Krasner, (1989): 17.

8 «En éste la atribución de recursos está determinada por los dotes y preferencias de los actores individuales que tienen el derecho de alienar su propiedad según sus propias estimaciones de sus mejores intereses» Krasner, (1989): 14.

${ }^{9}$ Krasner, (1989):14

${ }^{10}$ Esto refiere a presionar para que la distribución de recursos, poder, riquezas, estuvieran direccionados políticamente, atribuyéndolos de forma directa por parte de los países desarrollados, o indirectamente como por ejemplo por medio de la limitación de los derechos de propiedad de actores no estatales, incluyendo las corporaciones privadas Krasner, (1989): 15.

${ }^{11}$ Wallerstein, (1996): 119 y sgtes. 
mundial acerca de la inevitabilidad y legitimidad de la visión wilsonianoleninista, que incluía para ellos un plan de autodeterminación y luego desarrollo nacional como etapas necesarias para seguir asegurando la transferencia de plusvalía del Sur hacia el Norte. En esa visión, la Guerra Fría no existía sino como estrategia geopolítica de cada sector para asegurar el control sobre sus zonas de influencia, y la evidencia es que existió en esa etapa un equilibrio geopolítico congelado. Este conflicto orquestado, según el autor, contribuyó a la generación de un mundo unipolar en el que URSS fue funcional a otro periodo de acumulación capitalista, en el contexto de un sistema de economía mundo sostenido en una geo cultura de la modernidad.

En este orden puede leerse la invasión a Guatemala en 1954 para derrocar al gobierno de Arbenz, que había expropiado latifundios de la United Fruit como antesala de lo que vendría luego, catalizado por la revolución cubana y las posibilidades de su influencia en la región. Allí comienza el capítulo de la llamada Guerra Fría y la división de las zonas de influencia entre Estados Unidos y la Unión Soviética, que apoyaba a Cuba por sus propios motivos geopolíticos que confrontaron entonces a los motivos igualmente geopolíticos de los norteamericanos. Estados Unidos bajo la bandera del anticomunismo y el antisovietismo, desde 1960 y a lo largo de casi veinte años, apoyó o promovió golpes de Estado en Brasil, Argentina, Uruguay, Chile, El Salvador, Guatemala, República Dominicana, etc.

En todos los casos, al golpe le sucedía un gobierno que alteraba las frágiles, débiles reformas iniciadas por los gobiernos anteriores, en términos económicos orientadas hacia una planificación estatal que regulaba la libertad de mercados. «Los nuevos gobiernos recibían una inyección de capitales privados provenientes de las inversiones estadounidenses». ${ }^{12}$

A medida que el clima general abierto en los foros multilaterales internacionales sobre «préstamos y ayudas» a los países en desarrollo se asienta, Estados Unidos crea sus condiciones internas y externas para asegurar las inversiones de sus nacionales en América Latina. «..Y la Alianza para el Progreso mostró su verdadera cara», ${ }^{13}$ pues era obvio que estaba concebida para mantener la dependencia económica de América Latina, así, por ejemplo, los fondos no debían ser usados para proyectos de cambio estructural ni, entre otras condiciones, serían suministrados a quienes

${ }^{12}$ Agee, (1987): 434.

${ }^{13}$ Boersner, (1982):297. 
nacionalizaran empresas de propiedad privada. Se comprometía a los signatarios a la promoción de condiciones que estimularan la afluencia de inversiones extranjeras y el aseguramiento de promoción a las exportaciones de Estados Unidos hacia América Latina por medio de préstamos a compradores y seguros contra riesgo, ${ }^{14}$ y además $-\mathrm{y}$ claramente contra Cuba, como lo era la Alianza en general- establecía que no habría ninguna ayuda para países que permita que sus aviones o barcos transporten equipos o mercancías ese país. Las únicas reformas que la Alianza propiciaba eran las de tipo paternalista, vinculadas a un desarrollo económico en el marco del sistema de dependencia existente.

El Congreso norteamericano utiliza la Alianza para presionar sobre los derechos de expropiación de propiedades norteamericanas en América Latina con las condiciones allí impuestas y continúa con medidas en ese sentido; así la ley de Ayuda Exterior de Estados Unidos que prohíbe su utilización para beneficiar a un Estado que no «compense en el acto....en divisas extranjeras convertibles....y en su pleno valor las expropiaciones» ${ }^{15}$. Conforme Pérez Llana, las enmiendas Pelly, Conte, Hickenlooper, Symington $y$ Roess son algunas de las formas con que se determinan las condiciones de asistencia de Estados Unidos a los Estados que no aseguren la plena vigencia y el derecho de compensaciones a los nacionales estadounidenses en el extranjero. ${ }^{16}$

El Programa de Garantía de las Inversiones les asegura a los inversores estadounidenses en América Latina contra toda pérdida de sus inversiones a consecuencia de guerras, revoluciones o expropiaciones, asegurándolos también contra la imposibilidad de convertir sus ganancias en dólares. ${ }^{17}$ Esta capacidad de Estados Unidos de ser el asegurador de los riesgos de los privados norteamericanos, convirtió una cuestión transaccional privada en asuntos de Estado y dio lugar a una enmienda que interrumpía cualquier ayuda a todo país que no hubiese firmado el acuerdo de garantías antes del 31 de diciembre de 1966. «Se trataba de una amenaza eficaz y los acuerdos de garantía de las inversiones fueron firmados». ${ }^{18}$

Sin embargo, como sostenía Morray ${ }^{19}$ en aquella época «Los latinoamericanos tienen una habilidad especial para exasperar al gobierno de

\footnotetext{
${ }^{14}$ Morray,(1968): 104-105.

${ }^{15}$ Morray, (1968): 106.

16 Pérez Llana, (1973).

${ }^{17}$ Morray, (1968): 107.

${ }^{18}$ Morray, (1968): 108.

${ }^{19}$ Morray,( 1968): 97.
} 
Estados Unidos». .Así todo esto no transcurre sin enfrentamientos decididos y contrainsurgencias diplomáticas en la región Latinoamericana.

\section{Ideas y vocación autonomista}

Cuando Krasner se refiere a que los logros de la periferia en los foros multilaterales y organismos internacionales se debían, en parte, a la unidad de argumentos sostenidos por ésta, a la ideología emancipadora que los animaba y que manifestaban en esas décadas, no hacía sino dar cuenta de un pensamiento y una política, que en general recorrió América Latina en aquellos años y que en Argentina encuentra en los '70 manifestaciones políticas más integrales. ${ }^{20}$

En general la teorización sobre un pensamiento propio en América Latina sobre relaciones internacionales no surge sino hasta esa década y está cruzado por un concepto central, la autonomía, que aparece inicialmente desde la perspectiva de los ejes que vinculan desarrollo-dependencia con la subordinación política-independencia de la política exterior y, por lo tanto, parte de la dicotomía centro-periferia como eje ordenador de la asimetría estructural para explicar la dinámica del orden internacional.

Este tipo de reflexiones constituyeron enfoques auténticamente regionales de los años '70 orientados a desentrañar los mecanismos reales que permitieran superar la dependencia de los países periféricos, construir un «proyecto nacional ${ }^{21}$ entendido como un esfuerzo intelectual y político conjunto, que incluía no solo una clase dirigente consciente de la dominación y la necesidad de emancipación, sino una sociedad pensada a sí misma como «nacional», en tanto que busca sus auténticas vías de desenvolvimiento.

En Argentina el concepto de autonomía toma cuerpo por la obra de Juan Carlos Puig. Este hombre de acción política y estudioso-escritor construye un corpus teórico que le da forma al argumento central de la necesidad de una política exterior vinculada al papel de los países periféricos en relación a los bloques de poder internacional. Si bien su perspectiva atiende fundamentalmente al momento de la Guerra Fría y a la posición respecto de Estados Unidos y la Unión Soviética, que ordenaban la actuación de la periferia en términos de bloques dominantes, es innegable que su con-

\footnotetext{
${ }^{20}$ Krasner, (1989).

${ }^{21}$ Puig,(1984): 41.
} 
cepción teórica permite poner en perspectiva internacional y regional a la Argentina de entonces y pensar la vigencia de la categoría de autonomía como eje de política exterior.

En ese orden, Puig interpeló el mainstream de las disciplinas política exterior y relaciones internacionales de corte eurocéntrico, que implicó la utilización a-reflexiva de categorías ajenas a nuestra realidad y que en cierta medida siguen conduciendo algunos trabajos, en tanto eran teorías ideológicas que buscaban, con una cobertura cientificista, consolidar el poder de los países desarrollados y, por ende, carecían de validez para el análisis político capaz de otorgar fundamento a políticas y estrategias de los países periféricos.

El poder de dominación de los países centrales no aparecía como un conflicto a teorizar para el diseño de estrategias nacionales o regionales, pues más bien, la tradición en la región en materia de política exterior era de una casuística vinculada en su mayoría a reacciones de carácter reivindicativo en materia fundamentalmente de territorios. Por eso propuso lo que denomina una «teoría globalista», destinada a un tratamiento global y estructural de una política exterior latinoamericana «en tanto región periférica que mantiene vinculación dependentista -ora neocolonial, ora nacional- con el «centro», estructura politicoeconómica dominante, constituida por los países de desarrollo avanzados». ${ }^{22}$

Así, desde su condición de estudioso del derecho internacional público, puso en cuestión las concepciones centrales eurocéntrica en relaciones internacionales de entonces; tales como las de corte juridicista que afirmaba (y que sigue afirmando) que no existe un régimen internacional por carecer de coacción jurídica internacional y que, por lo tanto, es un sistema anárquico, así como que los fundamentos de la existencia de un orden internacional cohesivo se manifiesta en la voluntad de Estados caracterizados como iguales soberanos. O las de corte realista y liberal respecto a que las políticas exteriores están dirigidas por el Estado exclusivamente, actuando como un actor racional y coherente.

Por el contrario, argumenta que el régimen internacional existe $y$, como cualquier régimen del mundo social, está cohesionado por principios que tienen el poder de repartir potencia o impotencia a sus miembros, por parte de repartidores (países con poder) a los recipiendarios (países de la periferia). Esto promueve un ordenamiento jerárquico en los Estados, cuya actuación está entrecruzada por la voluntad e intereses de diver-

${ }^{22}$ Puig, Perez Llana, Monetta, (1973): 8. 
sos actores «que ostentan poder real e influyen en las decisiones a nivel internacional» ${ }^{23}$ y entonces «...para bien o para mal, la confrontación, que debe ser ineludiblemente estratégica, es inevitable» ${ }^{24}$ y para el desarrollo de estrategias de confrontación los países periféricos deben acumular recursos de poder y los más aptos son los que puedan ser utilizados en forma conjunta como poder de compra, movilización de la opinión pública, boicot exportador, club de deudores, integración política y otras formas.

En su perspectiva, todo planteamiento autonómico supone un contenido estratégico, en el sentido de que implica una dialéctica de voluntades que emplean la fuerza (en sentido amplio) para resolver el conflicto. La relación entre viabilidad e integración es clave para desarrollar autonomía. Viabilidad implica tanto condiciones nacionales (recursos, decisión, ideología emancipadora) como externa (situación que habilita el ejercicio del poder) e integración, entendida como la unión consciente entre los pares para el desarrollo de acciones conjuntas de poder de confrontación atendiendo a sus intereses.

La autonomía es «la máxima capacidad de decisión propia que se puede lograr teniendo en cuenta los condicionamientos objetivos del mundo real $\gg^{25}$ y para ello es clave la capacidad de análisis de los cuadros decisionales, para moverse en ese campo entre los condicionamientos del orden internacional y los propios intereses. Se desarrolla en grados y un perfil de política exterior caracterizado por la «autonomía heterodoxa» en palabras de Puig -la más emancipadora en un contexto de análisis de la viabilidadimplica diferenciar claramente qué intereses del país periférico se ponen en juego al momento de aceptar ciertas condiciones del hegemón (o quien tiene el poder hegemónico de entre los países centrales).

En este caso un país puede aceptar la conducción estratégica de una potencia dominante, como Argentina siguiendo el liderazgo de Estados Unidos, pero sus gobernantes «emancipadores» pueden discrepar y tomar medidas en consecuencia provenientes de su capacidad para diferenciar el modelo de desarrollo interno del país periférico respecto de los intereses del hegemón, diferenciando sus intereses de los del bloque también, encontrando convergencias o divergencias para acciones entre los países que los componen.

\footnotetext{
${ }^{23}$ Puig, (1973):49.

${ }^{24}$ Puig, (1984): 45.

${ }^{25}$ Puig, (1984): 76.
} 
Si hay un orden internacional de Estados, es porque hay hombres de carne y hueso que actúan operativizando dicho orden. Este es uno de los puntos que nos interesa destacar de la vasta obra de Puig; su análisis de los cuadros decisionales de un Estado periférico, que interpela a los decisores a clarificar cómo actúan y para quién al momento de ser recipiendarios y/ o repartidores de poder. Los repartidores supremos internacionales son los que imponen potencia o impotencia a escala mundial (Estados Unidos al momento de la Guerra Fría cuando Puig escribe), continental o regional. Los recipiendarios son los afectados por tales imposiciones.

Como sostiene Bologna, los repartidores no son los decisión-maker, sino realmente los que impulsan las decisiones, aunque formalmente otros la adopten. ${ }^{26}$ Se puede ser incluso repartidor intermedio internacional, por ejemplo un Jefe de Estado que decide eximir de impuestos a empresas extranjeras radicadas en su territorio.

El cuadro decisional para los Estados periféricos en relaciones internacionales es complejo, así diría Puig que el cuerpo de estrategas nacionales para actuar en los foros internacionales exige especialistas conocedores profundos de la realidad internacional, comprometidos ideológicamente con la emancipación, conocedores de las percepciones y representaciones de las élites y de los imaginarios sociales que están en los bloques de poder internacional y además observadores profundos de las propias representaciones sobre los legados históricos, porque todas estas consideraciones delinearán las acciones.

Deben manejarse sutilmente evaluando correctamente los márgenes potenciales de autonomía frente al poder de los grandes actores que dirigen el orden de repartos. Autonomizar significa ampliar el margen de decisión propia y, en un contexto de periferia, supone un juego estratégico previo de suma-cero, en el cual alguien gana lo que otro pierde. «Avanza el antiguo cliente, retrocede el antiguo dominante», ${ }^{27}$ esto implica adoptar una posición que se construye con recursos de poder de todo tipo pues: «no importa tanto la realidad tal cual es, sino como la «perciben» los que del otro lado adoptarán las decisiones estratégicas». ${ }^{28}$ Propone así una «introspección puigiana», una interpelación a que la élite decisional defina su posición frente al orden de repartos internacional y pueda preguntarse: ¿recipiendarios de quién y repartidores intermedios de quién? al momento

\footnotetext{
${ }^{26}$ Bologna, (2010).

${ }^{27}$ Puig, (1984): 45.

${ }^{28}$ Puig,( 1984): 45.
} 
de tomar una decisión en materia de política exterior o relaciones internacionales.

La primera lección es aprender a hacer la evaluación de los márgenes posibles de autonomía potencial y para ello desarrolla su concepción de los modos en que debe analizarse todo caso de conflicto, que bajo la cobertura de «jurídico» involucra la dimensión centro (dominante)-periferia (sujeta según sus grados de autonomía). Así en orden a la desmitificación del supuesto carácter resolutivo dado por el derecho a una situación internacional y, asumiendo que la tradición argentina en materia de diplomáticos ha sido la de ampararse en una lectura literal de la ley, permitiendo de esta manera que el sentido de la misma sea impuesto por la situación de poder del «centro», es que aborda al derecho desde una posición distinta.

«Todo fenómeno jurídico debe ser sometido al tratamiento sociológico, normativo y dikelógico (justicia), siguiendo la teoría trialista de Werner Goldschmidt en tanto el mundo jurídico es tridimensional». ${ }^{29}$ En esta se concibe al mundo jurídico como la integración de la realidad social, las normas y la justicia. Entonces hecho, norma y valor es la triada para el análisis del caso cuando se aspira a resolverlo no sólo desde la legalidad del mismo, sino desde la justicia en su resolución.

La manera en que se construye la solución a un problema internacional y que otorga poder de negociación a los conductores de políticas exteriores de los países periféricos involucrados en el mismo, es estudiando y elaborando argumentos que le den verosimilitud a la vinculación triádica. Como un verdadero instructivo de la aplicación de este enfoque, Puig analiza el «Caso de la International Petroleum Co.» (1973) en el que Perú expropia un complejo con campos petrolíferos de esa compañía extranjera y que apareja una complejidad enorme por los derechos involucrados, definida por las imposiciones de los capitales involucrados. En ese análisis Puig confirma que la manera de elegir los hechos sociales o normas de una manera jurídica para abordar un conflicto, consiste en hacerlo desde el punto de vista dikelógico.

\section{Argentina y la ruptura del bloqueo económico a Cuba}

Siguiendo la perspectiva de Puig afirmamos que en general la autonomía ha sido una nota de la política exterior de Argentina en tanto país

\footnotetext{
${ }^{29}$ Puig, (1973): 15.
} 
periférico; ha habido una tradición argentina de lucha por establecer una posición propia y autonómica. Pero la búsqueda de ese margen de decisión propia ha tenido diferentes grados de acuerdo al signo ideológico del gobierno (su clara motivación, su carácter emancipador de la dominación) así como del contexto internacional o sus grados de permisividad.

Las condiciones de permisividad del contexto para el desarrollo de la autonomía son claves. En otros momentos históricos de la Argentina, Puig reconoce vocación autonómica, así y solo para citar un ejemplo importante, Illia desafía a los capitales farmacéuticos extranjeros con la conocida «Ley Oñativia». Pero el resguardo de las inversiones norteamericanas y europeas por parte de un Estado fortalecido como Estados Unidos en ese contexto histórico impide la consolidación de estas acciones. ${ }^{30}$

Para 1970 Estados Unidos había llegado al apogeo y a los límites de su poder ${ }^{31}$ y la evaluación del margen posible de autonomía potencial era positivamente alto teniendo en cuenta una serie de factores que habían menguado el poder de «los grandes repartidores» (condiciones externas habilitadoras). El sistema financiero de Breton Woods había tenido un fuerte impacto por acciones de Estados Unidos, ${ }^{32}$ los «síndromes» cubanos y vietnamita, en el ámbito occidental, y polaco y afgano en el oriental, más la multipolarización económica que avanzaba con los $\mathrm{NIC}^{33}$ ponían en evidencia la declinación de un poder disciplinador de bloques por parte de Estados Unidos ${ }^{34}$.

La OPEP había demostrado el poder de una alianza de países del tercer mundo, boicoteando a los países desarrollados con sus recursos naturales, poniendo en evidencia su vulnerabilidad. Los foros multilaterales y las organizaciones internacionales daban lugar a proliferación de declaraciones, acuerdos y convenciones entre el Norte y el Sur, en los que éstos avanzaban en sus reclamos. A esto hay que agregar el desarrollo general, la expansión industrial y los avances de los países emergentes o en desarrollo. Todo esto eran muestras de la inhabilidad estratégica por parte de Estados Unidos y los países centrales.

\footnotetext{
${ }^{30}$ Esta ley, calificada de comunista por los sectores militares y las grandes empresas extranjeras, tuvo un peso decisivo en el proceso que culminaría con el derrocamiento del gobierno democrático de Ilia el 28 de junio de 1966.

${ }^{31}$ Wallerstein, (1985).

${ }^{32}$ Se refiere a la decisión de Nixon de en 1971 de no sostener la convertibilidad del dólar estadounidense a la tasa que se había convenido en el estatuto del FMI (Puig, 1986:52)

${ }^{33}$ Newly Industrialized Country.

${ }^{34}$ Puig,( 1986): 52.
} 
En este contexto, Argentina en 1973 está en condiciones de desarrollar, según la perspectiva de Puig, el pleno despliegue de la forma más acabada de la «autonomía heterodoxa», bajo el arco peronista. Esto era parte de un discurso fuertemente ideológico que emerge del corto momento peronista con Cámpora, Para ello su proyecto siguiendo la Tercera Posición de Perón propuesta en los años 40 y 50 pretendía insertar a la Argentina en un esquema de vinculaciones múltiples comerciales en áreas alternativas a las tradicionales de Estados Unidos y Europa, como Japón, América Latina y países del tercer mundo.

Entre éstos estaba Cuba. Conforme a Escudé, el establecimiento de un tipo de relaciones comerciales con este país puso en entredicho el bloqueo impulsado desde 1962 por Estados Unidos al régimen. ${ }^{35}$ Esto se designaría como el boicot argentino al embargo económico cubano y abrió un escenario de enfrentamientos diplomáticos entre Argentina y Estados Unidos de repercusión internacional.

El informe de la Comisión General de reunión entre países-CIES(con datos elaborados por la UAM de México en base a estadísticas del Dpto. del Estado norteamericano), afirmaba que:

«Estados Unidos controla el $50 \%$ de las inversiones totales en el mundo, el resto Reino Unido, Francia, Japón y Alemania. 561 empresas trasnacionales controlan el $91 \%$ de la inversión extranjera directa; otras empresas prefieren las industrias extractivas o conectadas con el transporte y otros servicios públicos. De las 10 empresas más grandes del mundo, 8 tienen sede en Estados Unidos. El $43 \%$ de inversión trasnacional fue para Argentina, Brasil, México, Venezuela, India y Nigeria». «Por 3 dólares de ganancia invierten 1 » «Sobresalen las intromisiones y prácticas monopólicas que ejercen a cambio de tecnologías y empleos». ${ }^{36}$

Había que contar además, como sostenía Dos Santos que las inversiones norteamericanas estaban cambiando el esquema clásico de la economía colonial latinoamericana, dirigiéndose cada vez más hacia los sectores manufactureros industriales antes que a los mineros y agrícolas, insertándose en un proceso de integración con los sectores nacionales de los países latinoamericanos, procediendo a dominar estos sectores capitalistas

\footnotetext{
${ }^{35}$ Escudé, (2000).

${ }^{36} \mathrm{La}$ Voz del Interior, 17/03/1973.
} 
industriales. ${ }^{37}$ En este esquema la autonomía heterodoxa implicaba utilizar esta realidad como ventaja, avanzando y retrocediendo cuando la oportunidad lo requiriera.

Si bien las relaciones entre Cuba y Argentina se reiniciaron en 1973, bajo el gobierno de Lanusse, el acercamiento efectivo se realiza bajo la Presidencia de Cámpora ${ }^{38}$. La dupla Puig ( en Política Exterior)-Gelbard (en Economía) fue clave, pues representaba la convergencia entre el pensamiento fuertemente cohesionado e ideológico de la Cancillería sobre política exterior y el proyecto que en lo económico sostenía Gelbard, líder de la CGE, asociación que representaba la industria mediana de capital nacional.

En agosto de 1973 el ministro Gelbard anunció el otorgamiento de un crédito de 200 millones de dólares a Cuba, lo que abrió un nuevo campo político comercial y que se ejecutaría bajo el arco de los cuatro gobiernos peronistas de ese periodo, en los cuales Gelbard fue funcionario.

La autonomía heterodoxa teorizada por Puig se desarrolla fundamentalmente bajo un esquema comercial que despliega los intereses de pequeños y medianos empresarios, tal como planteaba Gelbard y que hace converger los intereses de los pequeños empresarios nacionales con los que se estaban constituyendo como bloque capitalista trasnacional proveniente de las filiales norteamericanas radicadas en el país con los capitalistas industriales nacionales, tal como estudia Dos Santos. Los acuerdos con Cuba para la promoción y venta de empresas argentinas siguieron más allá de Cámpora, sobre todo desde Córdoba. ${ }^{39}$

El crédito comprendía una amplia gama de productos: tractores, autos, camiones, material ferroviario y otros elementos de transporte: construcción naval, máquinas, herramientas, equipos para la industria alimentaria y en general bienes de capital. «El enunciado era tan vasto que prácticamente comprendía todas las ramas de la industria argentina, tanto la constituida con capital nacional como extranjero». Se trataba de un préstamo anual por el término de seis años, lo cual significaba un monto total de 1200 millones de dólares, cifra extraordinaria «que representaba la mitad

\footnotetext{
${ }^{37}$ Dos Santos (1968): 91.

${ }^{38}$ Cabe recordar la presencia del Presidente cubano Dorticós durante la asunción de Cámpora y su participación en Córdoba en ocasión del cuarto aniversario del «Cordobazo».

${ }_{39}$ El presidente de la Federación Industrial de la Pcia. de Córdoba afirmaba entonces «..Estos acuerdos comerciales permiten atenuar los efectos deshumanizadores del bloqueo impuesto a Cuba».La Voz del Interior, 17/03/1974.
} 
del flujo de divisas que en un decenio salía del país con destino a Estados Unidos por concepto de royalties, giros bancarios y patentes industriales». ${ }^{40}$

Luego del anuncio del crédito a Cuba, se produce el «caso Krebs», forma con que se designó el enfrentamiento diplomático entre Argentina y el encargado de negocios de la Embajada de Estados Unidos, que abre un escenario de rispideces diplomáticas. Las leyes de radicación de capitales extranjeros, la defensa del trabajo nacional, la expropiación de bancos desnacionalizados, la repatriación de utilidades, la restricción de créditos internos para capitales foráneos eran el plexo de propuestas que constituían serias amenazas para los capitales estadounidenses radicados en el país ${ }^{41}$ tal cual lo manifiesta claramente el memorándum del encargado de negocios Krebs enviado a Gelbard. Pero además el informe fue producto de la reacción de la embajada norteamericana ante el fallo de la Corte Suprema argentina que no autorizaba a la empresa norteamericana Laboratorios Parke Davis a pagar menos impuestos por la merma de sus regalías, derivadas del uso de drogas de patente norteamericana en el mercado argentino. ${ }^{42} \mathrm{El}$ memorándum es considerado «improcedente por interferir en problemas exclusivamente argentinos» y discutido en el Congreso de la Nación donde se hizo un pronunciamiento de repudio declarando a Krebs «persona no grata». ${ }^{43}$

Si Estados Unidos era garante de las inversiones de sus capitales nacionales en Argentina, Argentina se convertía en promotor y garante de las inversiones argentinas en Cuba, diferenciando sus intereses económicos y su modelo de desarrollo nacional del anticomunismo estadounidense. Esto era sin dudas un grave desafío al hegemón, ya que se privilegiaba el interés nacional en tanto el acuerdo con Cuba abría un escenario ventajoso para las industrias nacionales e incluso potenciaba la expansión industrial argentina al variar la composición de las exportaciones, tradicionalmente formada por productos primarios.

En marzo de 1974 una misión de 200 empresarios argentinos, entre los cuales había representantes de la Standar Electric y General Motors de capitales norteamericanos y dirigentes gremiales argentinos, presencian el arribo del $1^{\circ}$ contingente de productos argentinos a Cuba, incluidos en el

\footnotetext{
${ }^{40}$ Bodes y López, (2003): 89-90.

${ }^{41}$ Córdoba, 01/08/1973.

${ }^{42}$ Moneta, (1988); Escudé, (2000).

${ }^{43}$ Córdoba, 01/08/1973.
} 
crédito de 1200 millones. Había maquinarias argentinas fabricadas en Pergamino y Santa Fe, además de yerba mate para refrescos. ${ }^{44}$ Se negociaron: provisión de porcelana y cristalería para equipar hoteles cubanos, libros de texto, impresión de libros cubanos en editoriales argentinas, convenios para la construcción de barcos en astilleros argentinos para la marina de Cuba.

La negociación, según palabras de Gelbard fue un «acuerdo para suministro de manufacturas por 500 millones de dólares, y se espera llegar a 600 milllones con plazo de ejecución de 3 años. El resto que queda de los 1200 milllones se está negociando» «Nos hemos circunscripto a las relaciones económicas para vender lo bueno de nuestra industria y tecnología», consultados sobre si esto rompe el bloqueo, Gelbard responde: «Nunca hemos pensado en el bloqueo a Cuba. El Presidente dijo que los bloqueos y particularmente el de Cuba son un trágico error». ${ }^{45}$

Pero el capítulo que dio lugar a que Argentina se convirtiera en noticia internacional del momento fue la parte del acuerdo de Argentina con Cuba vinculada a los autos. Cuba había manifestado su mayor interés en los autos de Ford, Chrysler y General Motors, que no podía adquirir a causa del bloqueo. La llamada venta de autos a Cuba implicó que empresas internacionales radicadas en la Argentina, mediante una acción concertada por el Gobierno, proyectaran la venta a Cuba de 42.000 unidades automotoras (camiones, tractores, autos, etc.), operación a 6 años de plazo, financiada con el crédito a Cuba. Una de las empresas oferentes, la Fiat, se encontraba fuera del área prohibida por el embargo, pues no era de capitales estadounidenses. Las otras tres eran filiales locales de centrales americanas -Chrysler, Ford y General Motors- susceptibles de que se les aplicara la legislación estadounidense que sancionaba a las empresas que no cumplían con los requisitos del bloqueo a Cuba. ${ }^{46}$

La estrategia de Gelbard chocó inicialmente con la resistencia de Krebs, quien anunció que el gobierno norteamericano prohibiría a las filiales argentinas de Ford, General Motors y Chrysler vender autos al mercado cubano. Argentina informa a Estados Unidos que no permitirá ninguna interferencia externa, estando obligadas las compañías radicadas a cumplir con los intereses del país o, de lo contrario, se expropiaría la pro-

\footnotetext{
${ }^{44}$ La Voz del Interior, 01/03/1974.

${ }^{45} \mathrm{La}$ Voz del Interior, 05/03/1974.

${ }^{46}$ De Imaz, (1974): 72.
} 
ducción de autos ${ }^{47}$ pagando su precio de lista para proceder después a su entrega por cuenta del gobierno argentino. ${ }^{48}$

Las empresas no reaccionaron negativamente ante este anuncio; por el contrario, manifestaron la voluntad de que el Estado argentino protegiera no solo sus inversiones en el país, sino el mismo acuerdo con Cuba. ${ }^{49}$ La polémica se acrecienta en 1974 cuando el Secretario del tesoro norteamericano Schultz, evidenciando la dilatación de la decisión como forma de presión sobre Argentina, advirtió que «el gobierno aún estaba estudiando la autorización para que las subsidiarias argentinas de Ford, Chrysler y General Motors vendieran autos a Cuba». ${ }^{50}$ A ello, Gelbard y Vignes (ya nuevo Ministro de Relaciones Exteriores) respondieron que las empresas, aun siendo filiales, estaban constituidas en la Argentina, como sociedades anónimas nacionales y solo sometidas a sus leyes. Eran libres para estipular los convenios que quisieren y no se requería autorización de la Casa Blanca. ${ }^{51}$

De Imaz recordaba que el laudo para el problema interno americano (es decir, la resolución del conflicto en ese país entre aplicar la ley federal o aceptar la extraterritorialidad de sus empresas) quedó en manos del presidente Nixon, quien finalmente el 18 de abril de 1974 autoriza a las filiales de las empresas estadounidenses a comerciar con Cuba: ${ }^{52}$

«Al parecer, en el laudo hubo que sopesar muchos elementos contradictorios; no sólo el enfrentamiento entre los intereses políticos del Estado y los económicos de las empresas, sino hasta la presión de las compañías competitivas que habían adherido al principio del bloqueo» ${ }^{53}$

Presiones que efectivamente el gobierno argentino había provocado, cerrando contratos de venta con empresas radicadas en Córdoba no comprometidas con el bloqueo como Fiat y Renault. ${ }^{54} \mathrm{Al}$ respecto señala

\footnotetext{
${ }^{47}$ Moneta, (1988): 75; Time, 29/04/1974.

${ }^{48}$ Bodes y López, (2003):95.

${ }^{49}$ Bodes y López, (2003): 121.

${ }^{50}$ Escudé, (2000): 182.

${ }^{51}$ Escudé,(2000): 182.

52 De Imaz (1974), 71.

${ }^{53}$ De Imaz, (1974): 72.

${ }^{54}$ Fiat Concord suscribió el 24 de agosto de 1974 tres contratos de venta a Cuba que incluía 6000 unidades de FIAT 125, 1500 tractores, 1035 camiones pesados, 20 ómnibus. «Cordobeses en Cuba» en Revista Aqui y Ahora año 4 . № 58 enero de 1974.
} 


\section{Escudé:}

«Esta movida del Ministro de Economía procuró explotar a su favor el temor de las empresas automotrices norteamericanas-y de sus filiales en la Argentina-a quedar excluidas del mercado cubano, en un contexto de recesión del sector en el mercado interno norteamericano, provocado por el impacto de la crisis petrolera» ${ }^{55}$

Las presiones se intensificaron por parte del mismo sector empresarial estadounidense; así daba cuenta el titular de un periódico cordobés: «Advierten en Estados Unidos sobre los riesgos de no comprender las políticas de Argentina hacia Cuba». El informe recogía las opiniones de un diario estadounidense especializado en cuestiones económicas que describía las «presiones de empresarios estadounidenses para que Estados Unidos no mezcle la política con la economía en el caso argentino cubano». ${ }^{56}$

\section{Nota de conclusión}

El caso Cuba llevado adelante por dirigentes políticos del gobierno argentino que perseguían objetivos autonómicos, una praxis instituida sobre principios de autonomía emancipadora, con contenidos pragmáticos, fue entendido como

«un acto de soberanía no sometido a la autorización de otros gobiernos y consecuencia de aplicar la receta de la autonomía heterodoxa: la apreciación nacional de que el bloqueo de Cuba consultaba más bien el interés nacional estadounidense antes que las preocupaciones estratégicas fundamentales de Occidente, se impuso en la práctica. Claro está que en el juego estratégico que precedió a la toma de decisión todas las variables fueron apreciadas debidamente, tanto desde el punto de vista estructural como coyuntural». ${ }^{57}$

La «operación Cuba», como se llamó a todo el proceso diplomático devenido de las relaciones comerciales que se entablaron entre ambos países, constituyó un episodio de enfrentamiento, de los tantos que ocurrían en los países periféricos en el contexto de la intervención norteamericana

\footnotetext{
${ }^{55}$ Escudé, (2000): 182.

${ }^{56} \mathrm{La} \mathrm{Voz}$ del Interior, 14/03/1974.

${ }^{57}$ Puig, (1984): 150.
} 
para asegurar las inversiones de sus capitales. La nota distintiva fue el desenlace de los acontecimientos; seguidos por los periódicos internacionales que registraban día a día la pulseada entre Argentina y Estados Unidos por el litigio ${ }^{58}$ siendo lo más paradigmático el incremento sustancial de poder de negociación que le otorgaron a Argentina, lo que podría designarse, en términos de un lenguaje autonomista, los flancos del hegemón.

Esto refiere a las alianzas entre los capitalistas industriales, nacionales y estadounidenses en la protección de sus intereses y actuando como factores de poder presionando para la autorización de Estados Unidos a la venta de los autos de las filiales en Argentina, en las que participaron también los sectores gremiales estadounidenses en defensa del trabajo del sector.

¿Era paradójico que la brecha que permitió un espacio de maniobra autonómico en Argentina se debiera a la «cooperación» de las empresas multinacionales? Estimamos que no lo era, en tanto evidenció, como sostenía Puig, que los actores con poder dentro de un Estado tienen, en ocasiones, una capacidad inusitada de forzar la dirección de la política exterior del Estado.

Así, en el informe de opinión del diario especializado en negocios estadounidenses se preguntaba: «iA quiénes deben servir las empresas trasnacionales; al país donde está la filial o a los intereses del país donde está la administración central? La respuesta es: A nadie» ${ }^{59}$.

Efectivamente a nadie, solo a los intereses asociados a la rentabilidad del capital. Por ello el caso cubano permite dimensionar la autonomía de medidas políticas, que sacan ventajas de esta lógica capitalista, direccionando sus efectos nacionalmente, según una perspectiva ideológica definida.

\section{Bibliografía}

AGEE, Paul, (1987), La CIA por dentro. Diario de un espia. Buenos Aires: Sudamericana.

BODES, José y LÓPEZ, José, (2003), Perón-Fidel. Linea directa. Cuando la Argentina rompió el bloqueo a Cuba. Buenos Aires: Memoria del Dragón.

\footnotetext{
${ }^{58}$ Bodes y López, (2003): 137.

${ }^{59} \mathrm{La} \mathrm{Voz}$ del Interior, 14/03/1974.
} 
BOERSNER, Demetrio, (1982), Relaciones Internacionales de América Latina. Caracas: Nueva Imagen.

BOLOGNA, Bruno, (2010), «La autonomía heterodoxa de la Política Exterior de Néstor Kirchner», en: BOLOGNA, Briceño y otros, $L a$ Política exterior del Cristina Fernández. Edición preparada por el CERIR. Tomo V. Rosario. UNR Editora.

DE IMAZ, José Luis, (1974) «¿Adiós a la teoría de la dependencia? Una perspectiva desde la Argentina» Revista Estudios Internacionales. $\mathrm{N}^{\circ}$ 28. Vol.7. Chile. Universidad de Chile. P 49-75.

DOS SANTOS, Theotonio, (1968), «La cambiante estructura de las inversiones extranjeras en América Latina» en: Petras, James y Zeitlin Maurice. comp. América Latina: ¿Reforma o Revolución? Buenos Aires: Tiempo Contemporáneo.

ESCUDÉ, Carlos, (2000), «Los gobiernos peronistas (1973-1976)» en Cisneros, Andrés y Escudé Carlos Historia general de las relaciones exteriores de la República Argentina. Tomo XIV Buenos Aires. Publicación del Centro de Estudios de Política Exterior y el CARI.

KRASNER, Stephen, (1989), Conflicto Estructural. El tercer mundo contra el liberalismo global. Buenos Aires: GEL.

MONETA, Juan Carlos, (1988), «La política exterior del peronismo: 19731976» en: Russell, Roberto y Perina, Raúl Argentina en el mundo (1973-1987), programa RIAL. Buenos Aires: GEL.

MORRAY, Joseph Parker, (1968), «Estados Unidos y América Latina» en: Petras, James y Zeitlin Maurice comp. América Latina: ¿Reforma o Revolución? Buenos Aires: Tiempo Contemporáneo.

PÉREZ LLANA, Carlos, (1973), «Perú en el sistema mundial y regional» en: PUIG, MONETA, PEREZ LLANA y CARELLA De la dependencia a la liberación. Politica exterior de América Latina. Buenos Aires: La Bastilla.

PUIG, Juan Carlos, (1973), «El caso de la International Petroleum CO.» en: PUIG, MONETA, PEREZ LLANA y CARELLA, De la dependencia a la liberación. Politica exterior de América Latina. Buenos Aires: La Bastilla.

PUIG, Juan Carlos, (1984), «La política exterior argentina: incongruencia epidérmica y coherencia estructural», en: PUIG, Juan Carlos (Comp.), América Latina: Politicas exteriores comparadas. Tomo 1. Buenos Aires: GEL. 
PUIG, Juan Carlos, (1986), «Integración y Autonomía de América Latina en las postrimerías del siglo XX». Revista Integración Latinoamericana. Cátedra INTAL. No 109 enero-febrero. Buenos Aires. pp 40-62

WALlERSTEIN, Immanuel, (1996), Después del Liberalismo. México: Siglo XXI. 